\title{
Nanopore sequencing reveals genomic map of CTX-M-type extended-spectrum $\beta$ - lactamases carried by Escherichia coli strains isolated from blue mussels (Mytilus edulis) in Norway
}

Didrik H. Grevskott ${ }^{1 \dagger}$, Francisco Salvà-Serra ${ }^{2,3,4,5,6 \dagger}$, Edward R. B. Moore $2,3,4,5$ and Nachiket P. Marathe ${ }^{1 *}$ (D)

\begin{abstract}
Background: Environmental surveillance of antibiotic resistance can contribute towards better understanding and management of human and environmental health. This study applied a combination of long-read Oxford Nanopore MinION and short-read Illumina MiSeq-based sequencing to obtain closed complete genome sequences of two CTX-M-producing multidrug-resistant Escherichia coli strains isolated from blue mussels (Mytilus edulis) in Norway, in order to understand the potential for mobility of the detected antibiotic resistance genes (ARGs).

Results: The complete genome sequence of strain 631 (E. coli sequence type 38) was assembled into a circular chromosome of $5.19 \mathrm{Mb}$ and five plasmids (between $98 \mathrm{~kb}$ and $5 \mathrm{~kb}$ ). The majority of ARGs cluster in close proximity to each other on the chromosome within two separate multidrug-resistance determining regions (MDRs), each flanked by IS26 transposases. MDR-1 carries bla TEM-1, tmrB, aac(3)-IId, aadA5, mph(A), mrx, sul1, aacE 1 and dfrA17; while MDR-2 harbors aph(3")-Ib, aph(6)-Id, bla $a_{\text {TEM-1, }}$ catA1, tet(D) and sul2. Four identical chromosomal copies of bla $a_{C \mathrm{TX}-\mathrm{M}-14}$ are located outside these regions, flanked by ISEC9 transposases. Strain 1500 (E. coli sequence type 191) exhibited a circular chromosome of $4.73 \mathrm{Mb}$ and two plasmids (91 kb and $4 \mathrm{~kb}$ ). The $91 \mathrm{~kb}$ conjugative plasmid belonging to Incl1 group carries bla $a_{\mathrm{CTX}-\mathrm{M}-15}$ and bla $a_{\mathrm{TEM}-1}$ genes.

Conclusion: This study confirms the efficacy of combining Nanopore long-read and Illumina short-read sequencing for determining complete bacterial genome sequences, enabling detection and characterization of clinically important ARGs in the marine environment in Norway, with potential for further dissemination. It also highlights the need for environmental surveillance of antibiotic resistance in low prevalence settings like Norway.
\end{abstract}

Keywords: Norway, Escherichia coli, ESBL, Nanopore, Genome sequence, MinION, Long-read sequencing, Antibiotic resistance

\footnotetext{
* Correspondence: nachiket.marathe@hi.no

${ }^{\dagger}$ Didrik H. Grevskott and Francisco Salvà-Serra contributed equally to this work.

${ }^{1}$ Department of Contaminants and Biohazards, Institute of Marine Research (IMR), Bergen, Norway

Full list of author information is available at the end of the article
}

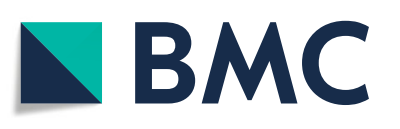

(- The Author(s). 2020 Open Access This article is licensed under a Creative Commons Attribution 4.0 International License, which permits use, sharing, adaptation, distribution and reproduction in any medium or format, as long as you give appropriate credit to the original author(s) and the source, provide a link to the Creative Commons licence, and indicate if changes were made. The images or other third party material in this article are included in the article's Creative Commons licence, unless indicated otherwise in a credit line to the material. If material is not included in the article's Creative Commons licence and your intended use is not permitted by statutory regulation or exceeds the permitted use, you will need to obtain permission directly from the copyright holder. To view a copy of this licence, visit http://creativecommons.org/licenses/by/4.0/. The Creative Commons Public Domain Dedication waiver (http://creativecommons.org/publicdomain/zero/1.0/) applies to the data made available in this article, unless otherwise stated in a credit line to the data. 


\section{Background}

Extended-spectrum $\beta$-lactamase (ESBL)-producing Enterobacteriaceae represent an emerging public health threat, for which research and urgent development of new antibiotics is needed [1]. Extended-spectrum $\beta$-lactamases are a group of enzymes that hydrolyze $\beta$-lactam antibiotics, including $3^{\text {rd }}$ generation cephalosporins [2]. These enzymes are divided into molecular class A, C and D, based on the protein sequences [3]. Among ESBLs, plasmid-mediated class A $\beta$-lactamases belonging to the CTX-M-type are prominent ESBLs in the clinics, especially in Europe $[4,5]$. CTX-M-producing Escherichia coli are dominated by a few high-risk clones, such as sequence type (ST) 131 and ST38 [6, 7]. E. coli ST131 and ST38 are recognized as enteroaggregative $E$. coli (EAEC) that can also cause extra-intestinal infections, including blood stream infection and urinary tract infection [8-10].

Environmental niches, including the aquatic environment, serve as a source of and/or a dissemination route for antibiotic resistance genes (ARGs) and resistant bacteria [11-14]. Clinically relevant ARGs and pathogens are introduced into the environment via different routes, such as through sewage contamination [15], waste from livestock production [16] and runoff from land [17]. Once introduced into the environment, ARGs and pathogens interact with environmental bacteria when sharing, at least temporarily, the same habitats [18]. Proximity and interactions within environmental niches provide opportunities for acquisition of resistance genes via horizontal transfer [18, 19]. Moreover, environmental pollution with antibiotics and other antimicrobial substances lead to selection of ARGs and resistant bacteria $[20,21]$. Such environments, thus, may be hotspots for further dissemination of ARGs and resistant bacterial strains.

The southern and eastern countries in Europe present high-risk of antimicrobial resistance (AMR) due to, in part, extensive use of antibiotics [22, 23]. For instance, the prevalence of invasive $E$. coli isolates resistant to $3^{\text {rd }}$ generation cephalosporins was $29.5 \%$ in Italy, in 2017 [22]. Accordingly, the prevalence of AMR in the environment was high [24], e.g., 15\% of the E. coli strains $(n=141)$ isolated from Venus clams (Chamelea gallina) in Italy carried ESBLs [25]. In contrast, Norway represents a low prevalence setting, in terms of antibiotic use [23] and prevalence of AMR [22]. The prevalence of ESBL-positive E. coli in Norway was 6.6 and $3.0 \%$ from blood and urine, respectively, in 2017 [26]. Although there is limited knowledge, the overall prevalence of AMR in the environment in Norway is low. In a previous study, we detected only two ESBL-positive E. coli strains (out of 199 analyzed), isolated from blue mussels (Mytilus edulis) in Norway [27].
With the advent of next-generation sequencing, whole-genome sequencing is increasingly used for resolving questions of bacterial taxonomy as well as for studying the genetic contents of particular strains [28]. Short-read sequencing technologies, such as Illumina and Ion Torrent, allow fragmented genome assembly, i.e., draft genome and, occasionally, complete closed genome sequences $[29,30]$. Draft genome sequences are suitable for detecting genes present in a given strain and for basic characterization and phylogenetic studies [31]. However, draft genome sequences do not reveal the complete metabolic potential of the given strains. Longread sequencing technologies, such as Oxford Nanopore and PacBio, allow assembly of complete genome sequences [32, 33], including the sequences of associated plasmids, which often carry metabolic genes and ARGs. However, owing to higher sequencing error rates associated with the long-read sequencing technologies, hybrid assembly using a combination of low-error short-reads as well as the long-reads, has been successfully applied to obtain reliable, complete closed genome sequences of bacterial strains [34].

The aim of this study was to apply a combination of long-read Nanopore and short-read Illumina-based sequencing to obtain high-quality complete genome sequences of the two ESBL-positive E. coli strains (631 and $1500)$ isolated from blue mussels (M. edulis) collected from coastal waters in Norway [27], in order to determine the genomic map of resistance genes and their potential for horizontal transfer.

\section{Results}

\section{Complete genome sequences of the two CTX-M-} producing E. coli strains

The Oxford Nanopore sequencing run generated 471,175 sequence reads for strain 631 and 576,474 sequence reads for strain 1500 , with average read length of $7.7 \mathrm{~kb}$ and $6.7 \mathrm{~kb}$, respectively. The longest read for strain 631 was $105,952 \mathrm{bp}$ and for strain 1500 was 125 , $266 \mathrm{bp}$. The average Phred quality score of the raw reads for Nanopore was 10.0 for both the strains (i.e., probability of error 0.1 ). The Nanopore-solo sequence assembly yielded six contigs for strain 631 and three contigs for strain 1500. The Illumina sequencing of strains 631 and 1500 generated 1,362,720 and 2,769,670 paired-end reads, respectively. After quality trimming, the average length of the reads was $227 \mathrm{bp}$ for strain 631 and $211 \mathrm{bp}$ for strain 1500 . The longest read was $251 \mathrm{bp}$ for both the strains. For Illumina reads, the average Phred quality scores of the trimmed reads were 34.5 for strain 631 and 34.9 for strain 1500 (i.e., probability of error $<0.001$ ). The assembly of Illumina-solo sequences produced 102 and 50 contigs (>500 bp) for strains 631 and 1500, respectively. 
In order to obtain highly accurate closed complete genome sequences of strains 631 and 1500, hybrid de novo assembly of Nanopore long-reads and Illumina short-reads was performed for each strain. The complete genome of strain 631 (GenBank accession number: CP040263-CP040268) was assembled into six contigs; one contig representing a complete circular chromosome of 5,191,486 bp and five plasmids, ranging from $97,726 \mathrm{bp}$ to $5165 \mathrm{bp}$ (Table 1). All ARGs, virulence genes (except for the espI gene detected on plasmid pEc631_1) and biocide/metal resistance genes (BMRGs) were located on the chromosome of this strain. Strain 1500 (GenBank accession number: CP040269-CP040271) exhibits a circular chromosome of 4,736,377 bp and two plasmids of $91,123 \mathrm{bp}$ and $4087 \mathrm{bp}$ (Table 1). This strain carries all virulence genes and BMRGs on the chromosome. However, $\beta$-lactamase genes $b l a_{\mathrm{CTX}-\mathrm{M}-15}$ and $b l a_{\mathrm{TEM}-1}$ are located on the plasmid pEc1500_CTX. Genome assembly statistics and complete overview of the genome sequences of strains 631 and 1500 are presented in Additional files 1 and 2, respectively. Additionally, a list of the virulence genes and BMRGs detected in strains 631 and 1500 (i.e., gene names and their function) are presented in Additional file 3. Conjugal transfer genes detected by searching through the GenBank files of the annotated genome sequences of strains 631 and 1500 are listed in Additional file 4.

\section{CTX-M-14 gene is located on the chromosome of $E$. coli strain 631}

Strain 631, belonging to ST38, carries all the ARGs on the chromosome (Table 1). The majority of ARGs are clustered together on the chromosome at two separate multidrug-resistance determining regions (MDRs), each flanked by IS26 transposases on either end. MDR-1 (25,149 bp), located between positions 1,184,422 - 1,209, $571 \mathrm{bp}$ on the chromosome, carries genes conferring resistance to penicillins, tunicamycin, aminoglycosides, macrolides, sulfonamides and trimethoprim (Fig. 1a). This region harbors $b l a_{\text {TEM-1 }}, \operatorname{tmr} B$, aac(3)-IId, aadA5, $m p h(A), m r x$, sul1, qacE $\Delta 1$ and $d f r A 17$ genes. Additionally, MDR-1 carries a chrA gene, conferring chromate resistance [35]. MDR-2 (19,772 bp), located between positions $4,406,649-4,426,421$ bp on the chromosome, carries genes conferring resistance to aminoglycosides, penicillins, amphenicols, tetracycline and sulfonamides (Fig. 1b). This region harbors aph(3")-Ib, aph(6)-Id, blaTEM-1, catA1, tet $(D)$ and sul2 genes. Four identical copies of the $b l a_{\mathrm{CTX}-\mathrm{M}-14}$ gene are present on the chromosome of strain 631. Two of the $b l a_{\text {CTX-M-14 }}$ copies are flanked by complete IS 5 and ISEc 9 transposases, while the remaining two copies are flanked by a truncated IS5 and a complete ISEC 9 transposase.
A single nucleotide polymorphism (SNP)-based phylogenetic tree shows that $E$. coli strain 631 is clustering closer to human isolates, compared to ST38 isolates from other animals, suggesting a possible human origin of strain 631 (Fig. 2). The number of SNPs between strains 631 and other ST38 strains is presented in Additional file 5.

\section{E. coli strain 1500 carries CTX-M-15 gene on a conjugative Incl1 plasmid}

The CTX-M-15-encoding plasmid pEc1500_CTX belonging to IncI1 group (GenBank accession number: CP040270) is $91,123 \mathrm{bp}$ and also carries $b l a_{\mathrm{TEM}-1}$ gene (Table 1). The bla $a_{\text {CTX-M-15 }}$ gene is located between positions $8445-9320 \mathrm{bp}$ on the plasmid, flanked by $\mathrm{Tn} 3$ and ISEc 9 transposases (Fig. 3). The ISEc 9 transposase flanking the $b l a_{\mathrm{CTX}-\mathrm{M}-15}$ gene in strain 1500 is identical $(100 \%)$ to the ISEc9 transposase flanking $b l a_{\mathrm{CTX}-\mathrm{M}-14}$ in strain 631, further supporting the role of ISEc9 transposase in dissemination of CTX-M-type ESBLs [36].

\section{Discussion}

To the best of our knowledge this is the first study reporting closed complete genome sequences of CTXM-producing E. coli strains (631 and 1500) isolated from blue mussels (Mytilus edulis) in Norway. In accordance with previous studies, we used a combination of Nanopore and Illumina sequencing and hybrid de novo assembly combining Nanopore long-reads with the accuracy of Illumina reads, for obtaining closed complete genome sequences [37-41].

The multidrug-resistant E. coli strain 631 (ST38) was resistant to 15 antibiotics [27]. ST38 is a known pathogenic sequence type of $E$. coli, usually associated with intestinal disease and sometimes extra-intestinal infection [8]. Despite the number of plasmids harbored by this strain, all the ARGs are located on the chromosome clustered together at two separate MDRs, both flanked by IS26 transposases. MDR-1 contains two DNA fragments $(17,687 \mathrm{bp}$ and $3094 \mathrm{bp}$, respectively) that are identical (>99.9\% nucleotide identity) to segments of a conjugative IncFII plasmid pE2855-3 $(92.7 \mathrm{~kb})$ reported in E. coli (GenBank accession number: AP018799) (Fig. 1a). MDR-1 also has DNA segments that are identical ( $>99.9 \%$ nucleotide identity) to segments of a plasmid, pVPS43 (19.4 kb), reported in Vibrio parahaemolyticus (GenBank accession number: KX957970). MDR-2 contains three DNA fragments (13,222 bp, $4188 \mathrm{bp}$ and $1176 \mathrm{bp}$, respectively) that are identical ( $>99.9 \%$ nucleotide identity) to segments of plasmid pKPN5 $(88.6 \mathrm{~kb})$, reported in Klebsiella pneumoniae (GenBank accession number: CP000650) (Fig. 1b). High identity of MDRs to the segments of plasmids carried by known pathogens, indicate that these regions are potentially mobile. Strain 631 carried four identical copies of the $b l a_{\mathrm{CTX}-\mathrm{M}-14}$ gene on the chromosome, flanked by 
Table 1 Overview of antibiotic resistance genes, virulence genes, biocide/metal resistance genes and conjugal transfer genes detected in Escherichia coli strains 631 (GenBank accession number: CP040263-CP040268) and 1500 (GenBank accession number: CP040269-CP040271) complete genome sequences

\begin{tabular}{|c|c|c|c|c|c|c|c|}
\hline Strain & Contig & Size (bp) & $\begin{array}{l}\text { Plasmid } \\
\text { type }\end{array}$ & $\begin{array}{l}\text { Antibiotic resistance } \\
\text { genes }\end{array}$ & Virulence genes $^{\alpha}$ & Biocide/metal resistance genes ${ }^{\beta}$ & Conjugal transfer genes ${ }^{\nu}$ \\
\hline \multirow[t]{6}{*}{631} & Chromosome & $5,191,486$ & - & $\begin{array}{l}\text { aac(3)-IId, aadA5, } \\
\text { aph(3")-Ib, aph(6)-Id, } \\
\text { bla }{ }_{\text {CTX-M-14, bla }} \text { TEM-11, } \\
\text { catA1, dfrA17, mph(A), } \\
\text { mrx, aacE } 1 \text {, sul1, } \\
\text { sul2, tet(D), tmrB }\end{array}$ & $\begin{array}{l}\text { ecpA-E, ecpR, elfAVG, } \\
\text { elfC-D, eaeH, hcpA-C, } \\
\text { papX, fimA-I, cah, ehaB, } \\
\text { airleaeX, upaG/ehaG, } \\
\text { upaH, ibeB-C, tia, chuA, } \\
\text { chuS-U, chuW-Y, sitA-D, } \\
\text { fyuA, irp1-2, ybtAVIX, } \\
\text { ybtP-Q, ybtS-U, } \\
\text { espL1/L4/R1/X1, espX4-5, } \\
\text { espY1-4, ACE T6SS-like } \\
\text { gene, aec11, aec15-19, } \\
\text { aec22-32, two SCI-I } \\
\text { T6SS-like genes, hlyE/clyA }\end{array}$ & 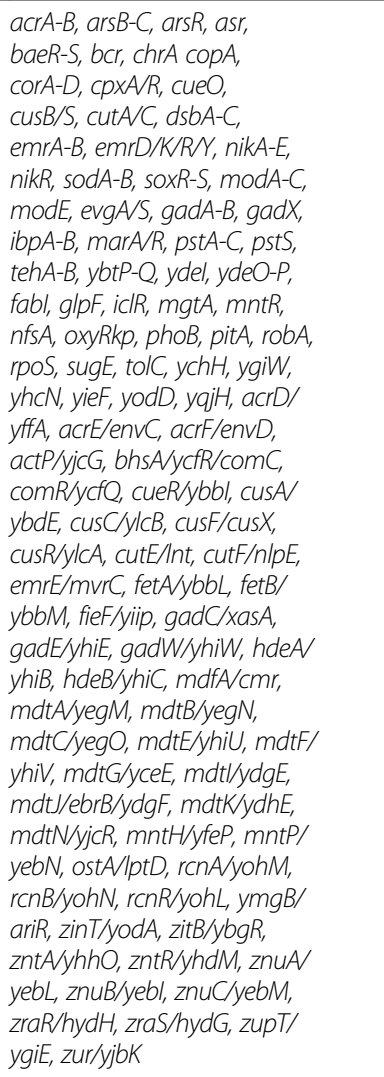 & None \\
\hline & $\begin{array}{l}\text { Plasmid } \\
\text { pEc631_1 }\end{array}$ & 97,726 & $\begin{array}{l}\operatorname{lncB/O/} \\
\mathrm{K} Z\end{array}$ & None & espl & None & $\begin{array}{l}\text { traX, traV, traT, traS, traR, } \\
\text { traQ, traO, traN, traM, } \\
\text { traJ, traF, traE, traC, trbC, } \\
\text { trbA, traW, traP }\end{array}$ \\
\hline & $\begin{array}{l}\text { Plasmid } \\
\text { pEc631_2 }\end{array}$ & 73,952 & IncFll & None & None & None & $\begin{array}{l}\text { traM, traY, traA, traL, traE, } \\
\text { traK, traB, traP, traV, traR, } \\
\text { traC, traW, traU, traN, } \\
\text { traF, traQ, traH, traG, } \\
\text { traT, traD, tral, traX, } \\
\text { trbB, trbC, trbE, trbF, } \\
\text { trbl, trbJ }\end{array}$ \\
\hline & $\begin{array}{l}\text { Plasmid } \\
\text { pEc631_3 }\end{array}$ & 30,240 & $\begin{array}{l}\text { IncFll } \\
\text { family }\end{array}$ & None & None & None & $\operatorname{trb} M, \operatorname{trbG}, \operatorname{trbl}$ \\
\hline & $\begin{array}{l}\text { Plasmid } \\
\text { pEc631_4 }\end{array}$ & 7464 & Col156 & None & None & None & None \\
\hline & $\begin{array}{l}\text { Plasmid } \\
\text { pEc631_5 }\end{array}$ & 5165 & Col156 & None & None & None & None \\
\hline 1500 & Chromosome & $4,736,377$ & - & None & $\begin{array}{l}\text { cfaA-E, eсpA-E, ecpR, } \\
\text { elfAGG, elfC-D, eaeH, } \\
\text { hcpA-C, fimA-I, ehaB, air/ } \\
\text { eaeX, upaG/ehaG, ibeB-C, } \\
\text { sitA-D, espL1/L4/R1/XI, } \\
\text { espX4-5, ACE T6SS-like } \\
\text { gene, aec15-18, } \\
\text { aec22-32, hlyE/clyA }\end{array}$ & 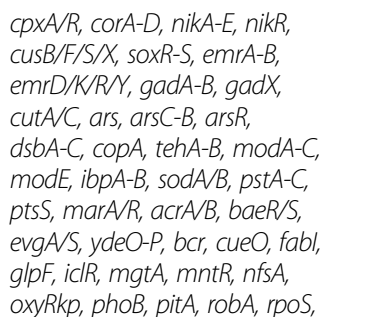 & None \\
\hline
\end{tabular}


Table 1 Overview of antibiotic resistance genes, virulence genes, biocide/metal resistance genes and conjugal transfer genes detected in Escherichia coli strains 631 (GenBank accession number: CP040263-CP040268) and 1500 (GenBank accession number: CP040269-CP040271) complete genome sequences (Continued)

\begin{tabular}{|c|c|c|c|c|c|c|c|}
\hline Strain & Contig & Size (bp) & $\begin{array}{l}\text { Plasmid } \\
\text { type }\end{array}$ & $\begin{array}{l}\text { Antibiotic resistance } \\
\text { genes }\end{array}$ & Virulence genes $^{\alpha}$ & Biocide/metal resistance genes ${ }^{\beta}$ & Conjugal transfer genes ${ }^{\gamma}$ \\
\hline & & & & & & 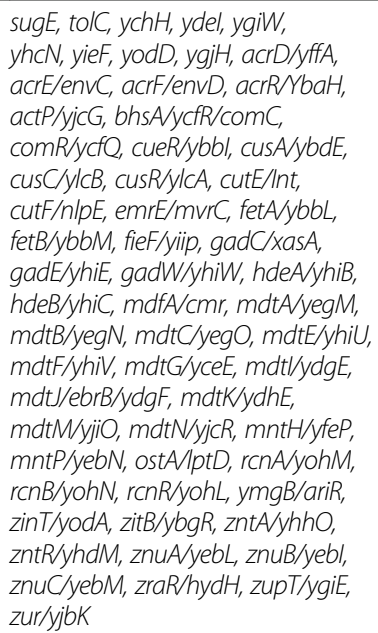 & \\
\hline & $\begin{array}{l}\text { Plasmid } \\
\text { pEc1500_CTX }\end{array}$ & 91,123 & Incl1 & $b l a_{C T X-M-15}, b l a_{T E M-1}$ & None & None & $\begin{array}{l}\operatorname{traX}, \operatorname{traV}, \operatorname{traT}, \operatorname{traS}, \operatorname{tra}, \\
\operatorname{traQ}, \operatorname{traP}, \operatorname{traO}, \operatorname{traN}, \\
\operatorname{traM}, \operatorname{traJ}, \operatorname{traE}, \operatorname{traC}, \operatorname{traA} \text {, } \\
\operatorname{traA}, \operatorname{trb} C, \operatorname{trb} \text {, traW, tral }\end{array}$ \\
\hline & $\begin{array}{l}\text { Plasmid } \\
\text { pEc1500 } 2\end{array}$ & 4087 & Col8282 & None & None & None & None \\
\hline
\end{tabular}

$\overline{\boldsymbol{a}, \boldsymbol{\beta}}$ Details about the virulence genes and biocide/metal resistance genes are provided in Additional file $3,{ }^{\boldsymbol{\gamma}}$ Details about the conjugal transfer genes are provided in Additional file 4

ISEc 9 transposases. Our results are in accordance with previous studies reporting chromosomal CTX-M genes in E. coli ST38 $[39,42]$. Although bla $a_{\mathrm{CTX}-\mathrm{M}-14}$ was detected on the chromosome of strain 631, the DNA fragment carrying $b l a_{\mathrm{CTX}-\mathrm{M}-14}$ and the flanking transposases, detected on the chromosome of strain 631, are identical (100\%) to segments of plasmids carried by different members of the family Enterobacteriaceae, including K. pneumoniae (GenBank accession number: CP041102), Salmonella enterica (GenBank accession number: MH522424) and Enterobacter cloacae (GenBank accession number: CP035635), suggesting that bla $a_{\mathrm{CTX}-\mathrm{M}-14}$ carried by strain 631 is mobile.

IncFII is a well-known plasmid family contributing to the worldwide spread of clinically relevant ARGs, particularly bla $a_{\mathrm{CTX}-\mathrm{M}-15}$ [43]. We detected two IncFII plasmids in strain 631, which did not carry ARGs. Even though this is quite unusual, IncFII plasmids without ARGs have been reported previously [44-47]. Further, our analysis showed that the MDR-1 on the chromosome of strain 631 has DNA segments that are identical ( $>99.9 \%$ nucleotide identity) to DNA segments of a conjugative IncFII plasmid reported in E. coli (GenBank accession number: AP018799) (Fig. 1a). This suggests a likelihood that the MDR regions in strain
631 may have been transferred from IncFII plasmid onto the chromosome by transposition [48].

E. coli strain 1500 carries CTX-M-15 gene on a conjugative IncI1 plasmid (pEc1500_CTX) that has high sequence identity (> 99.9\%) with plasmid pSH4469 (91.1 $\mathrm{kb}$ ), detected in CTX-M-15-producing Shigella sonnei (GenBank accession number: KJ406378) isolated from an outbreak in the Republic of Korea [49]. Plasmid pEc1500_CTX also has high identity (>99.9\%) with CTXM-carrying plasmid pEK204 $(93.7 \mathrm{~kb})$ from an E. coli strain (GenBank accession number: EU935740) reported in the UK [50]. The plasmid backbone also shares high identity $(>99.9 \%$ ) to a segment of $\sim 61 \mathrm{~kb}$ from plasmid pHNRD174 (86.2 kb) from E. coli (GenBank accession number: KX246268) reported in China. Although CTXM-14-encoding IncI1 plasmid has previously been reported in Norway [51], to the best of our knowledge, this is the first report on detection of $E$. coli carrying $b l a_{\mathrm{CTX}-\mathrm{M}-15}$ on an IncI1 plasmid in the marine environment in Norway. IncI1 plasmids are widely distributed within the family Enterobacteriaceae and are associated with dissemination of several ARGs [52]. The presence of CTX-M-15 gene on a conjugative IncI1 plasmid in strain 


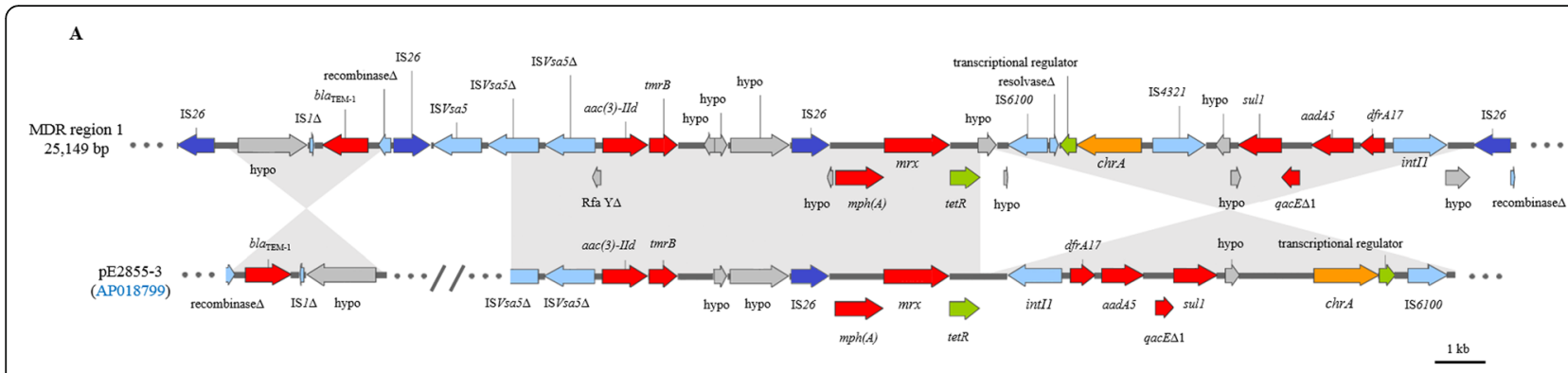

B

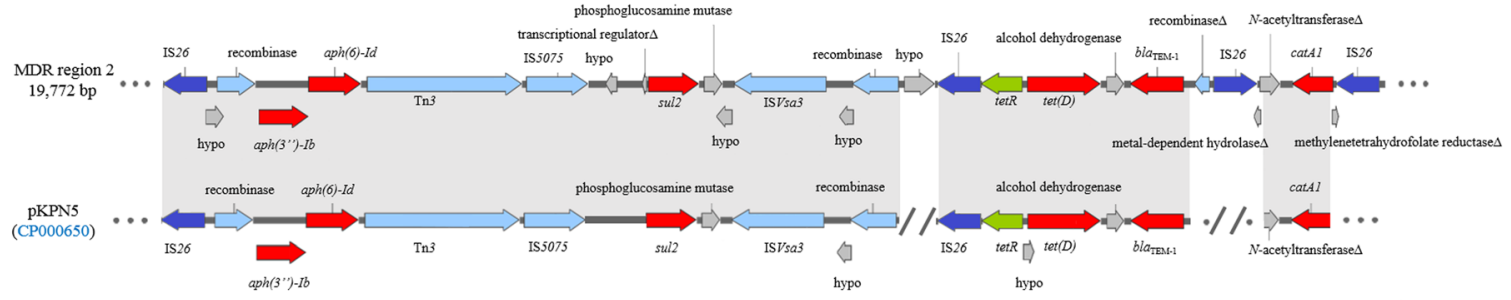

Fig. 1 Map of chromosomal multidrug-resistance determining regions (MDR) in Escherichia coli strain 631. a MDR-1, located on the chromosome between positions 1,184,422 - 1,209,571 bp, flanked by IS26 transposase, encoding bla TEM-1, aac(3)-IId, tmrB, mph(A), mrx, sul1, gacE 1 1, aadA5 and dfrA 17. b MDR-2, located on the chromosome between positions 4,406,649 - 4,426,421 bp, flanked by IS26 transposase, encoding aph(3")-Ib, $a p h(6)-I d, \operatorname{sul} 2$, tet(D), bla $\mathrm{TEM}_{\mathrm{T}-1}$ and catA1. Arrows indicate the sizes of the ORFs and their orientations in the genome. Antibiotic resistance genes are highlighted in red, IS26 transposases in dark blue, other transposases in blue, transcriptional regulators in green, metal resistance genes in orange and other genes are highlighted in dark grey. $\Delta$ represents truncated genes. Grey shaded regions represent $>99.9 \%$ nucleotide identity

1500 [27] highlights the potential for transfer of CTX-M15 to other environmental bacteria.

\section{Conclusion}

This study highlights the usefulness of hybrid assembly combining accurate short-reads and long-reads for obtaining closed complete genome sequences of strains
631 and 1500. Thus, enhancing the understanding of the genomic arrangement and potential for mobility of clinically important ARGs. It demonstrates the potential role of the marine environment in dissemination of pathogenic E. coli strains and clinically relevant ESBLs. These observations strengthen the notion that the environment plays an important role in dissemination of clinically

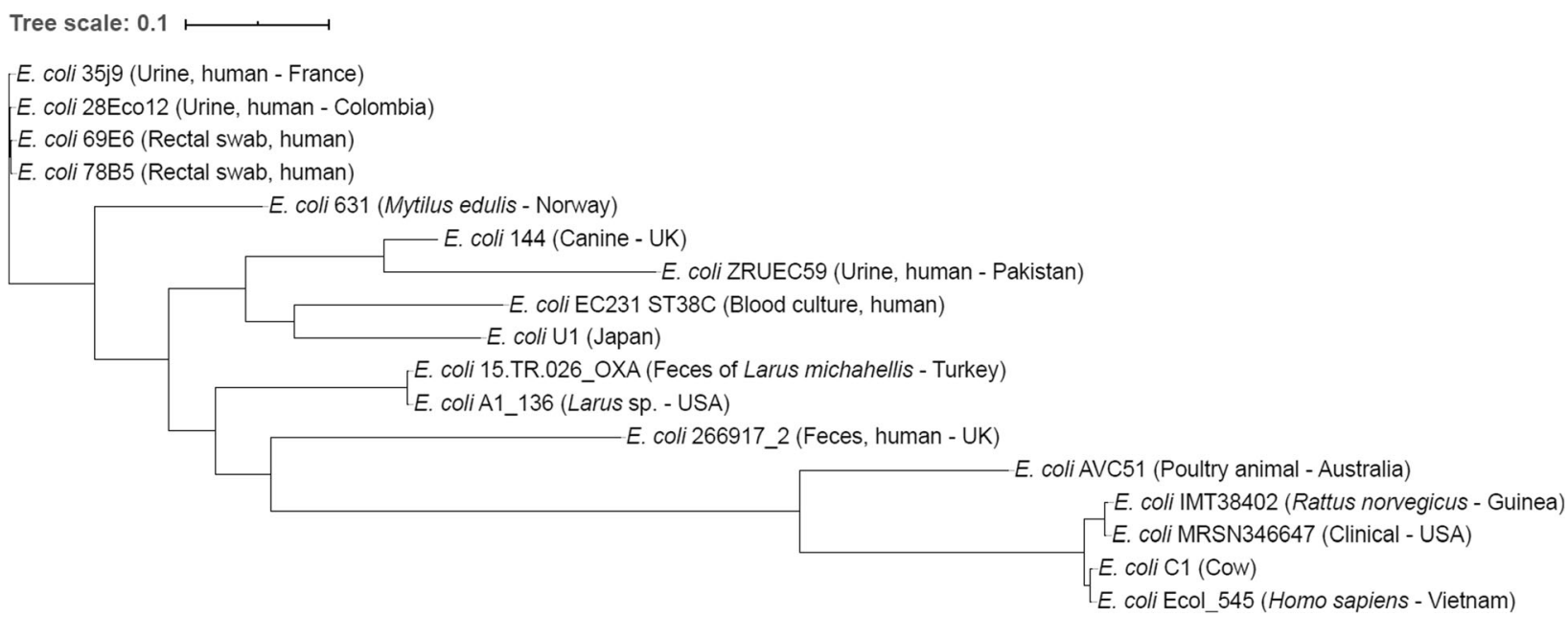

Fig. 2 Single nucleotide polymorphism (SNP)-based phylogenetic tree of Escherichia coli strain 631 and genome sequences of other strains of ST38 retrieved from GenBank 


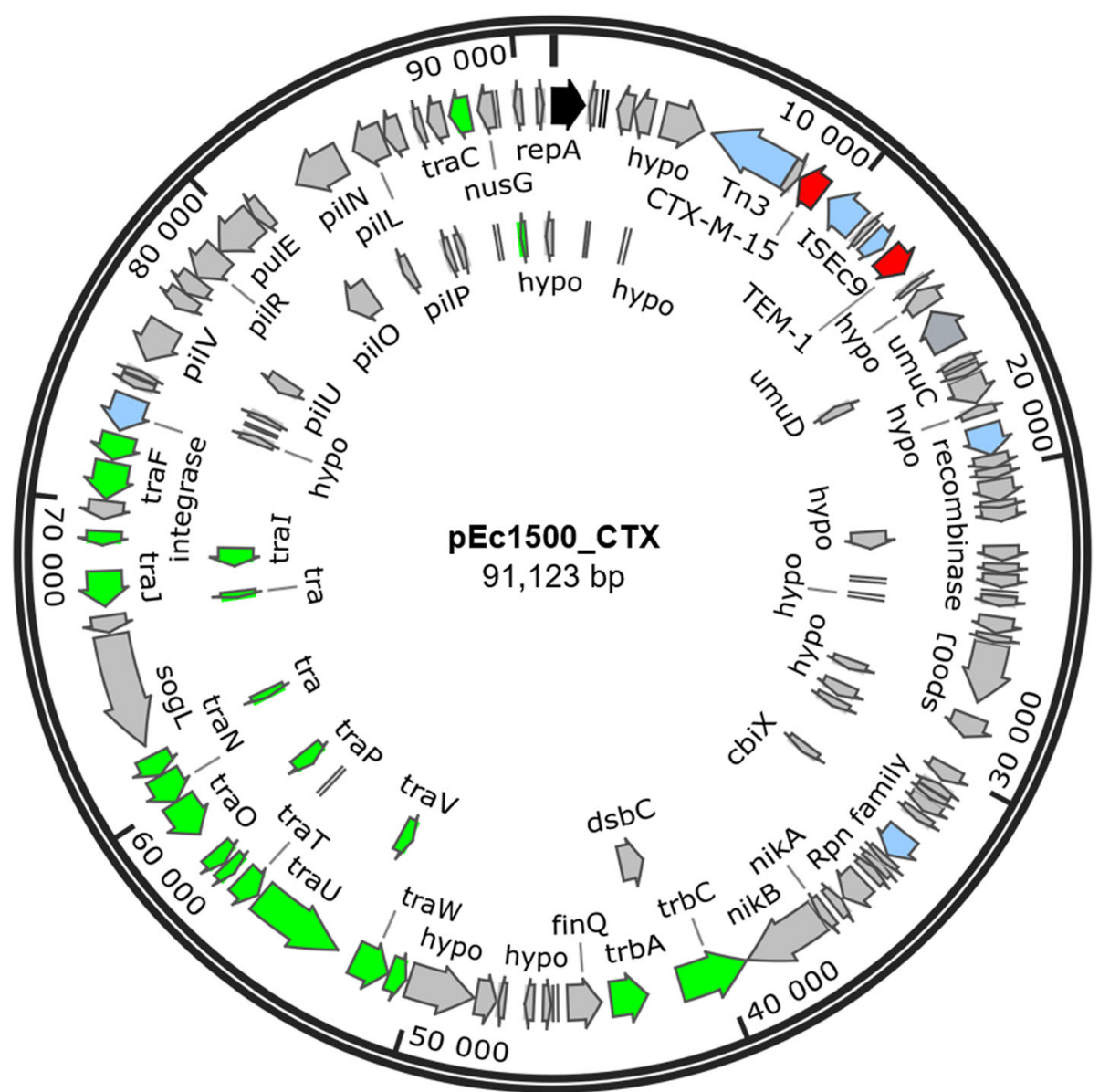

Fig. 3 Structure of plasmid pEC1500_CTX carrying bla sizes of the ORFs and their orientations in the genome. Antibiotic resistance genes are highlighted in red, transposases in blue, conjugal transfer genes in green, replication initiation gene in black and other genes are highlighted in grey

relevant ARGs and pathogens [13]. Our study also highlights the need for surveillance of antibiotic resistance in the environment, especially in a low prevalence setting like Norway, which would provide important insights for designing mitigation strategies for coping with resistance dissemination, before it becomes widespread.

\section{Methods}

\section{Bacterial strains, DNA extraction and sequencing}

E. coli strains 631 and 1500 were isolated from blue mussels (M. edulis) collected along the Norwegian coast, and characterized as described earlier [27]; the strains 631 and 1500 were denoted as strains B184 and B117, respectively, in Grevskott et al. 2017 [27]. E. coli strains 631 and 1500 were grown overnight on Mueller-Hinton $(\mathrm{MH})$ agar (Oxoid, UK) containing $2 \mu \mathrm{g} / \mathrm{mL}$ cefotaxime sodium salt (Sigma-Aldrich, USA) at $35^{\circ} \mathrm{C}$. For Illumina sequencing, genomic DNA was extracted from the strains using the MagNA Pure 96 DNA Small Volume kit and a MagNA Pure 96 instrument (Roche Diagnostics, Germany). For Oxford Nanopore sequencing, the extraction and purification of high-molecular weight DNA was achieved, following the protocol described by Salvà-Serra et al. [53]. The DNA was quantified, using NanoDrop $^{\text {tw }} 2000$ Spectrophotometer (Thermo Fisher, USA) assay and Qubit ${ }^{\text {th }} 2.0$ Fluorometer with the dsDNA BR (Broad-Range) kit (Thermo Fisher, USA). Integrity of the DNA (i.e., $>60,000 \mathrm{bp}$ ) was verified, using a Genomic ScreenTape kit, on a 2200 TapeStation system (Agilent Technologies, Inc., USA).

For Illumina sequencing, Kapa HyperPlus Library Preparation kit (Kapa Biosystems, USA) was used to prepare sequencing libraries. Sequencing was performed on Illumina MiSeq platform (Illumina, USA), using $2 \times 250$ bp chemistry, at the Public Health Institute, Oslo, Norway. For Nanopore sequencing, the sequencing library was prepared, using a Rapid Barcoding kit (Oxford Nanopore Technologies Ltd., UK). The library was 
sequenced, using a MinION sequencer and a FLO-MIN 106D Flow Cell version R9.4.1 (Oxford Nanopore Technologies Ltd., UK).

\section{Genome assembly and sequence analysis}

The raw reads generated by Illumina MiSeq were quality trimmed and assembled, using Trimmomatic version 0.36 [54] and SPAdes version 3.11.1 [55], respectively. The quality of the generated Illumina reads was analyzed with FastQC version 0.11.3 [56] and CLC Genomics Workbench version 12.0.3 (Qiagen, Denmark). The raw data generated by the MinION instrument were processed and demultiplexed with Guppy software version 2.3.7 (Oxford Nanopore Technologies Ltd.) and assembled using Canu version 1.8 [57]. The quality of the demultiplexed data was analyzed with NanoPlot version 1.26 .3 [58].

Subsequently, a hybrid de novo assembly of Illumina and Nanopore reads was performed, using Unicycler version 0.4.7 [34]. Assembly statistics were obtained, using QUAST server [59]. Average Nucleotide Identity values based on BLAST (ANIb) [60] were calculated, using the server JSpeciesWS [61], between E. coli strains 631, 1500 and E. coli DSM $30083^{\mathrm{T}}$ (GenBank accession number: AGSE00000000), to confirm the species identity. Genomes were annotated, using the Prokaryotic Genome Annotation Pipeline (PGAP) version 4.8 at the National Center for Biotechnology Information (NCBI) [62]. Complete overview of the genome sequences of strains 631 and 1500 were obtained, using GView Server version 1.7 [63]. Genetic maps were produced, using SnapGene ${ }^{\circ}$ software version 4.3.8.1 (GSL Biotech, USA). Multi-locus sequencing types (MLSTs) were examined, using the MLSTs tool described by Larsen et al. [64], with E. coli \#1 MLST profile [65]. Plasmid replicons were typed, using PlasmidFinder 2.0 [66], as well as BLASTP analysis of the replication initiation (Rep) sequence against the NCBI database. The presence of ARGs was examined, using ResFinder 3.2 [67] and CARD 3.0.7 [68]. Virulence genes were analyzed, using the Virulence Factors Database (VFDB) [69], and BMRGs were examined, using the BacMet database 2.0 [70], using the script BacMet-Scan.pl against the database of "Experimentally confirmed resistance genes". Conjugal transfer genes were examined by searching through the GenBank files of the annotated genome sequences of strains 631 and 1500.

\section{Comparative analysis of $E$. coli strain 631}

A SNP-based comparative analysis of the E. coli strain 631 (ST38) with other strains of identical ST from different sources and countries was performed as described by Sabat et al. [71]. Briefly, the assembled genome sequences in FASTA format were analyzed, using the tool
CSI Phylogeny 1.4 [72]. The parameters minimum depth at SNP positions, minimum relative depth at SNP positions, minimum distance between SNPs and minimum SNP quality were disabled, while the minimum read mapping quality and z-score were kept by default at 25 and 1.96, respectively. The SNP-based phylogenetic tree was displayed on-line with the Interactive Tree Of Life (iTOL) [73]. The details of the strains of E. coli ST38 included in the comparative analysis are presented in Additional file 6 .

\section{Supplementary information}

Supplementary information accompanies this paper at https://doi.org/10. 1186/s12866-020-01821-8.

Additional file 1. Assembly statistics of complete genome sequences of strains 631 and 1500 .

Additional file 2. Complete genome overview of CTX-M-producing Escherichia coli strains 631 (A) and 1500 (B).

Additional file 3. List of virulence genes and biocide/metal resistance genes detected in strains 631 and 1500 (i.e., names and their function).

Additional file 4. List of genes involved in conjugal transfer detected in strains 631 and 1500 .

Additional file 5. Single nucleotide polymorphism differences in Escherichia coli strains 631 compared with E. coli ST38 strains from different sources and countries.

Additional file 6. List of Escherichia coli ST38 strains included in the single nucleotide polymorphism (SNP)-based analysis.

\section{Abbreviations \\ AMR: Antimicrobial resistance; ANIb: Average nucleotide identity values based on BLAST; ARGs: Antibiotic resistance genes; BMRGs: Biocide/metal resistance genes; ESBL: Extended-spectrum $\beta$-lactamase; iTOL: Interactive Tree Of Life; MDRs: Multidrug-resistance determining regions; MH: Mueller-Hinton; MLSTs: Multi-locus sequence types; NCBI: National Center for Biotechnology Information; PGAP: Prokaryotic Genome Annotation Pipeline; SNP: Single nucleotide polymorphism; ST: Sequence type; VFDB: Virulence Factors Database}

\section{Acknowledgments}

The authors thank Marianne Sunde at the Norwegian Veterinary Institute, and Gina Ilaug Guldahl, Nadia Debech and Ingerid Kirkeleite at the

Norwegian Institute of Public Health for their help. The authors acknowledge Bjørn Tore Lunestad and Cecilie Smith Svanevik for their support to this work. The computations were partially performed on resources provided by the Swedish National Infrastructure for Computing (SNIC) through Uppsala Multidisciplinary Center for Advanced Computational Science (UPPMAX) under Project SNIC 2019/8-176.

\section{Authors' contributions}

NM conceived the study. DG, FS, EM and NM performed the experiment and data analysis. DG, FS and NM wrote the manuscript. EM provided critical inputs for the completion of the manuscript. All authors have read and approved the manuscript.

\section{Funding}

DG received PhD funding from the Institute of Marine Research. NM acknowledges Institute of Marine Research for funding under the Ocean Health program, Project number: 15495. FS and EM acknowledge support from the Swedish Västra Götaland Region (Lab Medicine Project number: 51060-6268) and from the University of Gothenburg Global Challenges project and Centre for Antibiotic Resistance Research (CARe), Project number: 205314021. The Culture Collection University of Gothenburg (CCUG) is supported by the Department of Clinical Microbiology, Sahlgrenska University Hospital and the Sahlgrenska Academy of the University of Gothenburg. 


\section{Availability of data and materials}

The assembled genome sequences are submitted to GenBank under accession numbers: CP040263-CP040268 and CP040269-CP040271, respectively. Strains 631 and 1500 are available at the Culture Collection University of Gothenburg (CCUG; www.ccug.se) under the numbers CCUG 73937 and CCUG 73938, respectively.

\section{Ethics approval and consent to participate}

Not applicable.

\section{Consent for publication}

Not applicable.

\section{Competing interests}

The authors declare that they have no competing interests.

\section{Author details}

'Department of Contaminants and Biohazards, Institute of Marine Research (IMR), Bergen, Norway. ${ }^{2}$ Department of Infectious Diseases, Institute of Biomedicine, Sahlgrenska Academy, University of Gothenburg, Gothenburg, Sweden. ${ }^{3}$ Culture Collection University of Gothenburg (CCUG), Sahlgrenska Academy, Gothenburg, Sweden. ${ }^{4}$ Centre for Antibiotic Resistance Research (CARe), University of Gothenburg, Gothenburg, Sweden. ${ }^{5}$ Department of Clinical Microbiology, Sahlgrenska University Hospital, Region Västra Götaland, Gothenburg, Sweden. ' ${ }^{6}$ Microbiology, Department of Biology, University of the Balearic Islands, Palma de Mallorca, Spain.

\section{Received: 10 February 2020 Accepted: 12 May 2020}

\section{Published online: 25 May 2020}

\section{References}

1. World Health Organization (2017). Global priority list of antibiotic-resistant bacteria to guide research, discovery, and development ofnew antibiotics. Geneva: World Health Organization. http://www.who.int/medicines/ publications/WHO-PPL-Short_Summary_25Feb-ET_NM WHO.pdf. Accessed 5 Feb 2020.

2. Pfeifer Y, Cullik A, Witte W. Resistance to cephalosporins and carbapenems in gram-negative bacterial pathogens. Int J Med Microbiol. 2010;300(6):3719.

3. Bush K. Past and present perspectives on $\beta$-lactamases. Antimicrob Agents Chemother. 2018;62(10):1-20.

4. Cantón R, González-Alba JM, Galán JC. CTX-M enzymes: origin and diffusion Front Microbiol. 2012;3(110):1-19.

5. Bevan ER, Jones AM, Hawkey PM. Global epidemiology of CTX-M $\beta$ lactamases: temporal and geographical shifts in genotype. J Antimicrob Chemother. 2017;72(8):2145-55.

6. Peirano G, Pitout JDD. Extended-spectrum $\beta$-lactamase-producing Enterobacteriaceae: update on molecular epidemiology and treatment options. Drugs. 2019;79(14):1529-41.

7. Pitout J. Extraintestinal pathogenic Escherichia coli: A combination of virulence with antibiotic resistance. Front Microbiol. 2012;3(9).

8. Chattaway MA, Jenkins C, Ciesielczuk H, Day M, DoNascimento V, Day M Rodríguez I, van Essen-Zandbergen A, Schink A-K, Wu G, et al. Evidence of evolving extraintestinal enteroaggregative Escherichia coli ST38 clone. Emerg Infect Dis. 2014:20(11):1935-7.

9. Pitout J, DeVinney R: Escherichia coli ST131: A multidrug-resistant clone primed for global domination. F1000Res 2017;6(195).

10. van der Bij AK, Peirano G, Pitondo-Silva A, Pitout JDD. The presence of genes encoding for different virulence factors in clonally related Escherichia coli that produce CTX-Ms. Diagn Microbiol Infec Dis. 2012;72(4):297-302.

11. Forsberg KJ, Reyes A, Wang B, Selleck EM, Sommer MOA, Dantas G. The shared antibiotic resistome of soil bacteria and human pathogens. Science. 2012;337(6098):1107-11.

12. Karkman A, Pärnänen K, Larsson DGJ. Fecal pollution can explain antibiotic resistance gene abundances in anthropogenically impacted environments. Nat Commun. 2019:10(1):1-8.

13. Bengtsson-Palme J, Kristiansson E, Larsson DGJ. Environmental factors influencing the development and spread of antibiotic resistance. FEMS Microbiol Rev. 2018;42:68-80.

14. Wellington EM, Boxall AB, Cross P, Feil EJ, Gaze WH, Hawkey PM, JohnsonRollings AS, Jones DL, Lee NM, Otten W. The role of the natural environment in the emergence of antibiotic resistance in gram-negative bacteria. Lancet Infect Dis. 2013:13(2):155-65.

15. Marathe NP, Pal C, Gaikwad SS, Jonsson V, Kristiansson E, Larsson DGJ. Untreated urban waste contaminates Indian river sediments with resistance genes to last resort antibiotics. Water Res. 2017;124:388-97.

16. Zhu Y-G, Johnson TA, Su J-Q, Qiao M, Guo G-X, Stedtfeld RD, Hashsham SA, Tiedje JM. Diverse and abundant antibiotic resistance genes in Chinese swine farms. PNAS. 2013;110(9):3435-40.

17. Heuer H, Schmitt H, Smalla K. Antibiotic resistance gene spread due to manure application on agricultural fields. Curr Opin Microbiol. 2011;14(3): 236-43.

18. Martínez JL. Bottlenecks in the transferability of antibiotic resistance from natural ecosystems to human bacterial pathogens. Front Microbiol. 2012; 2(265):1-6.

19. Aminov Rl. Horizontal gene exchange in environmental microbiota. Front Microbiol. 2011;2(158):1-19.

20. Marathe NP, Regina VR, Walujkar SA, Charan SS, Moore ERB, Larsson DGJ, Shouche YS. A treatment plant receiving waste water from multiple bulk drug manufacturers is a reservoir for highly multi-drug resistant integronbearing bacteria. PLoS One. 2013;8(10):1-10

21. Zhou Q, Wang M, Zhong X, Liu P, Xie X, Wangxiao J, Sun Y. Dissemination of resistance genes in duck/fish polyculture ponds in Guangdong province: correlations between $\mathrm{cu}$ and $\mathrm{Zn}$ and antibiotic resistance genes. Environ Sci Pollut R. 2019;23(8):8182-93.

22. ECDC: European Centre for Disease Prevention and Control (ECDC). Surveillance of antimicrobial resistance in Europe - Annual report of the European Antimicrobial Resistance Surveillance Network (EARS-Net) 2017. In. Stockholm: ECDC; 2018.; 2017: p. 1-29.

23. EMA. European Medicines Agency (EMA), European Surveillance of Veterinary Antimicrobial Consumption, 2018. 'Sales of veterinary antimicrobial agents in 30 European countries in 2016'. (EMA/275982/2018). In.; 2016: p. 26-32

24. Colombo S, Arioli S, Neri E, Della Scala G, Gargari G, Mora D. Viromes as genetic reservoir for the microbial communities in aquatic environments: a focus on antimicrobial-resistance genes. Front Microbiol. 2017;8(1095):1-13.

25. Vignaroli C, Di Sante L, Leoni F, Chierichetti S, Ottaviani D, Citterio B, Biavasco F. Multidrug-resistant and epidemic clones of Escherichia coli from natural beds of Venus clam. Food Microbiol. 2016;59(2016):1-6.

26. NORM/NORM-VET: Usage of Antimicrobial Agents and Occurrence of Antimicrobial Resistance in Norway. In. Tromsø / Oslo 2019. ISSN:1502-2307 (print) / 1890-9965 (electronic); 2018: p.10-12;29-33.

27. Grevskott DH, Svanevik CS, Sunde M, Wester AL, Lunestad BT. Marine bivalve mollusks as possible indicators of multidrug-resistant Escherichia coli and other species of the Enterobacteriaceae family. Front Microbiol. 2017; 8(24):1-10.

28. Quainoo S, Coolen JPM, van Hijum SAFT, Huynen MA, Melchers WJG, van Schaik W, Wertheim HFL. Whole-genome sequencing of bacterial pathogens: the future of nosocomial outbreak analysis. Clin Microbiol Rev. 2017:30(4):1015-63.

29. Bentley DR, Balasubramanian S, Swerdlow HP, Smith GP, Milton J, Brown CG, Hall KP, Evers DJ, Barnes CL, Bignell HR, et al. Accurate whole human genome sequencing using reversible terminator chemistry. Nature. 2008; 456(7218):53-9.

30. Rothberg JM, Hinz W, Rearick TM, Schultz J, Mileski W, Davey M, Leamon JH, Johnson K, Milgrew MJ, Edwards M, et al. An integrated semiconductor device enabling non-optical genome sequencing. Nature. 2011;475(2011):348-52.

31. Tyler S, Tyson S, Dibernardo A, Drebot M, Feil EJ, Graham M, Knox NC, Lindsay LR, Margos G, Mechai S, et al. Whole genome sequencing and phylogenetic analysis of strains of the agent of Lyme disease Borrelia burgdorferi from Canadian emergence zones. Sci Rep. 2018;8(1):1-12.

32. Rhoads A, Au KF. PacBio sequencing and its applications. Genom Proteom Bioinf. 2015:13(5):278-89.

33. Loman NJ, Quick J, Simpson JT. A complete bacterial genome assembled de novo using only nanopore sequencing data. Nat Methods. 2015;12(2015): 733-5.

34. Wick RR, Judd LM, Gorrie CL, Holt KE. Unicycler: resolving bacterial genome assemblies from short and long sequencing reads. PLoS Comput Biol. 2017; 13(6):1-22.

35. Aguilar-Barajas E, Paluscio E, Cervantes C, Rensing C. Expression of chromate resistance genes from Shewanella sp. strain ANA-3 in Escherichia coli. FEMS Microbiol Lett. 2008;285(1):97-100. 
36. Zhao W-H, Hu Z-Q. Epidemiology and genetics of CTX-M extendedspectrum $\beta$-lactamases in gram-negative bacteria. Crit Rev Microbiol. 2013; 39(1):79-101.

37. De Maio N, Shaw LP, Hubbard A, George S, Sanderson ND, Swann J, Wick R, AbuOun M, Stubberfield E, Hoosdally SJ, et al. Comparison of long-read sequencing technologies in the hybrid assembly of complex bacterial genomes. Microb Genom. 2019;5(9):1-12.

38. Goldstein S, Beka L, Graf J, Klassen JL. Evaluation of strategies for the assembly of diverse bacterial genomes using MinION long-read sequencing. BMC Genomics. 2019;20(1):1-23.

39. Greig DR, Dallman TJ, Hopkins KL, Jenkins C. MinION nanopore sequencing identifies the position and structure of bacterial antibiotic resistance determinants in a multidrug-resistant strain of enteroaggregative Escherichia coli. Microb Genom. 2018;4(10):1-5.

40. Salvà-Serra F, Jaén-Luchoro D, Jakobsson HE, Gonzales-Siles L, Karlsson R, Busquets A, Gomila M, Bennasar-Figueras A, Russell JE, Fazal MA et al: First complete genome sequences of Streptococcus pyogenes NCTC 8198T and CCUG 4207T, the type strain of the type species of the genus Streptococcus: 100\% match in length and sequence identity between PacBio solo and Illumina plus Oxford Nanopore hybrid assemblies. bioRxiv 2020.

41. Wick RR, Judd LM, Gorrie CL, Holt KE. Completing bacterial genome assemblies with multiplex MinION sequencing. Microb Genom. 2017;3(10):1-7.

42. Rodríguez I, Thomas K, Van Essen A, Schink AK, Day M, Chattaway M, Wu G, Mevius D, Helmuth R, Guerra B. Chromosomal location of blactx-m genes in clinical isolates of Escherichia coli from Germany, the Netherlands and the UK. Int J Antimicrob Agents. 2014;43(6):553-7.

43. Coque TM, Novais A, Carattoli A, Poirel L, Pitout J, Peixe L, Baquero F, Cantón $\mathrm{R}$, Nordmann P. Dissemination of clonally related Escherichia coli strains expressing extended-spectrum $\beta$-lactamase CTX-M-15. Emerg Infect Dis. 2008;14(2):195-200.

44. Carattoli A, Villa L, Pezzella C, Bordi E, Visca P. Expanding drug resistance through integron acquisition by IncFI plasmids of Salmonella enterica Typhimurium. Emerg Infect Dis. 2001;7(3):444-7.

45. Carattoli A, Bertini A, Villa L, Falbo V, Hopkins KL, Threlfall EJ. Identification of plasmids by PCR-based replicon typing. J Microbiol Methods. 2005;63(3):219-28.

46. García A, Navarro F, Miró E, Villa L, Mirelis B, Coll P, Carattoli A. Acquisition and diffusion of bla $a_{\mathrm{CTX}-\mathrm{M}-9}$ gene by R478-InCHI2 derivative plasmids. FEMS Microbiol Lett. 2007;271(1):71-7.

47. Villa L, García-Fernández A, Fortini D, Carattoli A. Replicon sequence typing of IncF plasmids carrying virulence and resistance determinants. J Antimicrob Chemother. 2010;65(12):2518-29.

48. Rubio-Cosials A, Schulz EC, Lambertsen L, Smyshlyaev G, Rojas-Cordova C, Forslund K, Karaca E, Bebel A, Bork P, Barabas O. Transposase-DNA complex structures reveal mechanisms for conjugative transposition of antibiotic resistance. Cell. 2018;173(1):208-20.

49. Kim JS, Kim J, Jeon S-E, Kim SJ, Kim N-O, Hong S, Kang Y-H, Han S, Chung GT. Complete nucleotide sequence of the Incl1 plasmid pSH4469 encoding CTX-M-15 extended-spectrum $\beta$-lactamase in a clinical isolate of Shigella sonnei from an outbreak in the Republic of Korea. Int J Antimicrob Agents. 2014:44(6):533-7.

50. Woodford N, Carattoli A, Karisik E, Underwood A, Ellington MJ, Livermore DM. Complete nucleotide sequences of plasmids pEK204, pEK499, and pEK516, encoding CTX-M enzymes in three major Escherichia coli lineages from the United Kingdom, all belonging to the international O25:H4-ST131 clone. Antimicrob Agents Chemother. 2009;53(10):4472-82.

51. Naseer U, Haldorsen B, Tofteland S, Hegstad K, Scheutz F, Simonsen GS, Sundsfjord A, GROUP TNES: Molecular characterization of CTX-M-15producing clinical isolates of Escherichia coli reveals the spread of multidrug-resistant ST131 (O25:H4) and ST964 (O102:H6) strains in Norway APMIS 2009, 117(7):526-536.

52. Carattoli A. Resistance plasmid families in Enterobacteriaceae. Antimicrob Agents Chemother. 2009;53(6):2227-38.

53. Salvà-Serra F, Svensson-Stadler $L$, Busquets $A$, Jaén-Luchoro D, Karlsson R, R B. Moore E, Gomila M: A protocol for extraction and purification of highquality and quantity bacterial DNA applicable for genome sequencing: A modified version of the Marmur procedure. Protoc Exch 2018.

54. Bolger AM, Lohse M, Usadel B. Trimmomatic: a flexible trimmer for Illumina sequence data. Bioinformatics. 2014;30(15):2114-20.

55. Bankevich A, Nurk S, Antipov D, Gurevich AA, Dvorkin M, Kulikov AS, Lesin VM, Nikolenko SI, Pham S, Prjibelski AD. SPAdes: a new genome assembly algorithm and its applications to single-cell sequencing. J Comput Biol. 2012:19(5):455-77.

56. Andrews S. (2010). FastQC: a quality control tool for high throughput sequence data. Available online at: http://www.bioinformatics.babraham.ac. uk/projects/fastqc. Accessed 8 Sep 2018

57. Koren S, Walenz BP, Berlin K, Miller JR, Bergman NH, Phillippy AM. Canu: scalable and accurate long-read assembly via adaptive $k$-mer weighting and repeat separation. Genome Res. 2017:1-36.

58. De Coster W, D'Hert S, Schultz DT, Cruts M, Van Broeckhoven C. NanoPack: visualizing and processing long-read sequencing data. Bioinformatics. 2018; 34(15):2666-9.

59. Gurevich A, Tesler G, Vyahhi N, Saveliev V. QUAST: quality assessment tool for genome assemblies. Bioinformatics. 2013;29(8):1072-5.

60. Goris J, Konstantinidis KT, Klappenbach JA, Coenye T, Vandamme P, Tiedje JM. DNA-DNA hybridization values and their relationship to whole-genome sequence similarities. Int J Syst Evol Microbiol. 2007;57(1):81-91.

61. Richter M, Rosselló-Móra R, Glöckner FO, Peplies J. JSpeciesWS: a web server for prokaryotic species circumscription based on pairwise genome comparison. Bioinformatics. 2015;32(6):929-31.

62. Tatusova T, DiCuccio M, Badretdin A, Chetvernin V, Nawrocki EP, Zaslavsky L, Lomsadze A, Pruitt KD, Borodovsky M, Ostell J. NCBI prokaryotic genome annotation pipeline. Nucleic Acids Res. 2016:44(14):6614-24.

63. Petkau A, Stuart-Edwards M, Stothard P, Van Domselaar G. Interactive microbial genome visualization with GView. Bioinformatics. 2010;26(24): 3125-6.

64. Larsen MV, Cosentino S, Rasmussen S, Friis C, Hasman H, Marvig RL, Jelsbak L, Pontén TS, Ussery DW, Aarestrup FM. Multilocus sequence typing of total genome sequenced bacteria. J Clin Microbiol. 2012;50:1355-61.

65. Wirth T, Falush D, Lan R, Colles F, Mensa P, Wieler LH, Karch H, Reeves PR, Maiden MCJ, Ochman H, et al. Sex and virulence in Escherichia coli: an evolutionary perspective. Mol Microbiol. 2006;60(5):1136-51.

66. Carattoli A, Zankari E, García-Fernández A, Larsen M, Lund O, Villa L, Aarestrup F, Hasman $\mathrm{H}$. In Silico detection and typing of plasmids using PlasmidFinder and plasmid multilocus sequence typing. Antimicrob Agents Chemother. 2014;58(7):3895-903.

67. Zankari E, Hasman H, Cosentino S, Vestergaard M, Rasmussen S, Lund O, Aarestrup FM, Larsen MV. Identification of acquired antimicrobial resistance genes. J Antimicrob Chemother. 2012;67(1 1):2640-4.

68. Alcock BP, Raphenya AR, Lau TTY, Tsang KK, Bouchard M, Edalatmand A, Huynh W, Nguyen A-LV, Cheng AA, Liu S et al: CARD 2020: Antibiotic resistome surveillance with the comprehensive antibiotic resistance database. Nucleic Acids Res. 2019. In press.

69. Liu B, Zheng D, Jin Q, Chen L, Yang J. VFDB 2019: a comparative pathogenomic platform with an interactive web interface. Nucleic Acids Res. 2019;47(D1):D687-92.

70. Pal C, Bengtsson-Palme J, Rensing C, Kristiansson E, Larsson DGJ. BacMet: antibacterial biocide and metal resistance genes database. Nucleic Acids Res. 2014:42(D1):D737-43.

71. Sabat AJ, Hermelijn SM, Akkerboom V, Juliana A, Degener JE, Grundmann H, Friedrich AW. Complete-genome sequencing elucidates outbreak dynamics of CA-MRSA USA300 (ST8-spa t008) in an academic hospital of Paramaribo, Republic of Suriname. Sci Rep. 2017;7(1):41050.

72. Kaas RS, Leekitcharoenphon P, Aarestrup FM, Lund O. Solving the problem of comparing whole bacterial genomes across different sequencing platforms. PLoS One. 2014:9(8):e104984.

73. Letunic I, Bork P. Interactive tree of life (iTOL) v3: an online tool for the display and annotation of phylogenetic and other trees. Nucleic Acids Res. 2016;44(W1):W242-5.

\section{Publisher's Note}

Springer Nature remains neutral with regard to jurisdictional claims in published maps and institutional affiliations. 